\title{
A study of association between dental health status and pregnancy
}

\author{
Bhavana Gupta $^{1 *}$, Attiuddin Siddique ${ }^{2}$
}

\begin{abstract}
${ }^{1}$ Associate Professor, Department of Obstetrics and Gynecology, ${ }^{2}$ Department of Dentistry, Integral Institute of Medical Sciences and Research, Dasauli, Post Basha, Kursi Road, Lucknow-226026, Uttar Pradesh, India
\end{abstract}

Received: 1 September 2013

Accepted: 21 September 2013

\author{
*Correspondence: \\ Dr. Bhavana Gupta, \\ E-mail: bhavana_yajat@yahoo.com
}

(C) 2013 Gupta B et al. This is an open-access article distributed under the terms of the Creative Commons Attribution Non-Commercial License, which permits unrestricted non-commercial use, distribution, and reproduction in any medium, provided the original work is properly cited.

\begin{abstract}
Background: To study the association between dental health status and pregnancy in rural India.

Methods: The cohort study was carried out in the department of Obstetrics and Gynecology at Integral Institute of Medical Sciences and Research, Lucknow from March 2012 to April 2013, for the period of 1year. The dental health statuses of 600 antenatal cases were studied. The prevalence of gingivitis, dental caries and periodontal disease were studied. The association between poor oral hygiene, gingivitis and dental caries were studied in the pregnant women.

Results: In the study the prevalence of dental caries, gingivitis and periodontal disease were $90 \%, 98 \%$ and $90.33 \%$ respectively. The antenatal cases with poor oral hygiene were 2.5 times more likely to have dental caries. OR 0.0138 , $95 \%$ CI $(0.0033$ to 0.0570$) \mathrm{Z}$ statistic 5.908, $\mathrm{P}<0.0001$. The antenatal cases with poor oral hygiene were 20 times more likely to have gingivitis (OR $0.0045,95 \%$ CI (0.0006-0.0365) Z statistic 5.077, $\mathrm{P}<0.0001)$.
\end{abstract}

Keywords: Pregnancy, Gingivitis, Dental caries, Periodontal disease

\section{INTRODUCTION}

An old quote, "with each child, a tooth" holds place in dental and medical literature. The increase in circulating levels of estrogen and progesterone in second month of pregnancy and continuous rise till eight month is reflected in increase in gingival inflammation during pregnancy. Increased level of progesterone cause capillary permeability and gingival exudates. Estrogen causes change in keratinisation of gingival epithelium. The anaerobic flora prevotella intermedia, bacteroides increase during $13^{\text {th }}$ week and remain high in third trimester. Apart from gingivitis, other diseases affecting pregnant women are dental caries, periodontitis and pregnancy granuloma. Current evidence suggest an association between periodontal diseases and increased risk of systemic disease such as atherosclerosis, myocardial infraction, stroke, diabetes mellitus and adverse pregnancy outcome including preterm birth, low birth weight, abortion and preeclampsia. Some data have shown scaling root planning to pregnant women with periodontitis may reduce the risk of preterm birth.

\section{METHODS}

The cohort study was carried out in the department of obstetrics and gynecology at Integral Institute of Medical Sciences and Research, Lucknow from March 2012 to April 2013 for a period of 1 year. The institution caters the medical and dental needs of rural population of central Uttar Pradesh. The antenatal cases in the first trimester attending the OPD were counseled and after the consent were registered in the study. The detailed sociodemographic history of cases, age, parity, socioeconomic status, education, religion, obstetric history were taken. A detailed history of addiction to tobacco/pan was taken. The hygiene of the cases were assessed by the brushing habits (with brush/fingers). Use of tooth paste/gul (local ayurvedic preparation) as practiced in the community in the rural setup, was elicited. The sample was grouped into symptomatic and asymptomatic groups. All the cases were subjected to routine dental examination on OPD basis. The WHO criteria, 'newly developed cavity (dental caries) and gingival bleeding on probing (gingivitis)', was taken into 
consideration. The oral hygiene was evaluated by examination and questionnaire.

The two components the debris/plaque (DI) and the calculus (CI) were used to calculate the oral hygiene index (OHI-S index=DI+CI). The OHI-S index <1 was considered good and OHI-S index $\geq 1$ was considered poor. The questionnaire pertaining to dental health care included the knowledge, attitude and behavioral habits. The cases were further categorized depending on the oral disease into cases treated conservatively (medicine and oral hygiene) and cases treated by procedure (scaling) in second trimester and the untreated group. The prevalence of gingivitis, dental caries and periodontitis in pregnant women were studied along with the associated factors. The cases were subsequently followed up in each trimester, and the prognosis and response to dental care education, hygiene and treatment was evaluated. A logistical model was applied to calculate the odds ratio (OR) and 95\% confidence interval (CI) of risk factors for dental caries and gingivitis. A p-value of $<0.05$ was considered statistically significant.

\section{RESULTS}

In the present study, a total of 600 antenatal cases were studied for a period of 1 year. The subjects were in the first trimester. The history and the dental health status of cases were elicited by using a proforma. The cases were classified into symptomatic and asymptomatic cases. $86.7 \%$ of cases were symptomatic and $13.3 \%$ of cases were asymptomatic. The commonest symptom was bleeding from gums on brushing (84\% of cases). Other symptoms were pain, loose tooth and sensitivity. The above symptoms were conspicuously noticed in the beginning of second trimester in $86 \%$ of cases and in $14 \%$ of cases symptoms were preexisting before pregnancy and got aggravated in the second trimester. 588 cases had gingivitis, 540 had dental caries and 542 cases had periodontal disease. The prevalence of dental caries, gingivitis and periodontal disease were $90 \%, 98 \%$ and $90.33 \%$ respectively. Among the cases with periodontal disease bleeding on probing was the commonest finding (62.5\%), supragingival and subgingival calculus (22.6\%), and pockets (14.9\%). $68.60 \%$ of cases were given oral hygiene instruction only (twice daily brushing with fluoride paste). $18.97 \%$ of cases were given oral amoxicillin, paracetamol and advise regarding oral hygiene.

$43 \%$ of cases required scaling, plaque removal, oral antibiotic and oral hygiene. The procedure was timed in the second trimester. The cases were subsequently followed up in second and third trimester. There was a significant improvement in the oral health in the second and third trimester in the treated group compared to the untreated group. The OHI-S index showed perfect oral hygiene in $0 \%$, good oral hygiene in $15.24 \%$, satisfactory hygiene in $56.64 \%$ and bad oral hygiene in $28.12 \%$ of cases. The OHI-S index $<1$ was considered good and $\geq 1$ was considered bad. Poor hygiene and illiteracy/low education status was significant predictor of dental caries and gingivitis. Those cases with poor oral hygiene were 20 times more likely to have gingivitis than those practicing good hygiene. Odds ratio 0.0045 , 95\% CI (0.0006 -0.0365) Z statistic 5.077, P-value $<0.0001$. The pregnant women with poor dental care were 2.5 times more at risk of caries than those practicing good dental care (Odds ratio $0.0138,95 \%$ CI (0.0033-0.570), Z statistic 5.908, P-value <0.0001).

Table 1: Dental diseases in pregnant women.

\begin{tabular}{|lll|}
\hline Dental disease & $\begin{array}{l}\text { Pregnant } \\
\text { women } \\
\text { Number (total } \\
\text { cases 600) }\end{array}$ & $\begin{array}{l}\text { Percentage } \\
\%\end{array}$ \\
\hline Caries & & \\
\hline Yes & 540 & $90 \%$ \\
\hline No & 60 & $10 \%$ \\
\hline Gingivitis & & $98 \%$ \\
\hline Yes & 588 & $2 \%$ \\
\hline No & 12 & \\
\hline
\end{tabular}

Table 2: Association of dental caries and oral hygiene status in pregnant women.

\begin{tabular}{|lllll|}
\hline $\begin{array}{l}\text { Oral hygiene } \\
\text { status }\end{array}$ & \multicolumn{2}{l|}{$\begin{array}{l}\text { Caries } \\
\text { Number }\end{array}$} & \multicolumn{2}{l|}{$\begin{array}{l}\text { No Caries } \\
\text { Number } \%\end{array}$} \\
\hline Good & 154 & $28.5 \%$ & 58 & $96.7 \%$ \\
\hline Poor & 386 & $71.5 \%$ & 2 & $3.3 \%$ \\
\hline
\end{tabular}

$\mathrm{OR}=0.0138,95 \% \mathrm{CI}(0.0033-0.0570)$

$\mathrm{Z}$ statistic 5.908, P-value $<0.0001$

Table 3: Association of gingivitis and oral hygiene status in pregnant women.

\begin{tabular}{|lllll|}
\hline $\begin{array}{l}\text { Oral } \\
\text { hygiene } \\
\text { status }\end{array}$ & $\begin{array}{l}\text { Gingivitis } \\
\text { Number } \%\end{array}$ & \multicolumn{2}{l|}{$\begin{array}{l}\text { No gingivitis } \\
\text { Number } \%\end{array}$} \\
\hline Good & 28 & $4.8 \%$ & 11 & $91.7 \%$ \\
\hline Poor & 560 & $95.2 \%$ & 1 & $8.3 \%$ \\
\hline
\end{tabular}

$\mathrm{OR}=0.0045,95 \% \mathrm{CI}(0.0006-0.0365)$

Z-statistics 5.077, P-value $<0.0001$

\section{DISCUSSION}

The increase in estrogen and progesterone secretion in pregnancy causes gingivitis, gingival hyperplasia, pyogenic granuloma, salivary changes and dental caries. ${ }^{1}$ The effect is first noticeable in the second month of gestation and peaks in eight month. Some recent studies 
have shown the prevalence of gingivitis $86.2-98.8 \%$. The prevalence of dental caries $74 \%$. The frequency of pyogenic granuloma varies from $0-9.6 \% .^{2,3}$ In our study, we found the prevalence of dental caries, gingivitis and periodontal disease were $90 \%, 98 \%$ and $90.33 \%$ respectively. The high prevalence of dental disease can be attributed to poor hygiene, low literacy and low socioeconomic status in the study group. Studies have shown a higher prevalence of gingivitis and dental caries among pregnant women with poor oral hygiene and low education status. ${ }^{4,5}$ In our study, the cases with poor oral hygiene were 2.5 times more likely to have dental caries and 20 times more likely to have gingivitis. The periodontal disease has been associated with increased risk of preterm birth, low birth weight, preeclampsia and intrauterine growth retardation. The periodontal disease represents an infectious disease affecting more than $23 \%$ of women between the age group 30-54 years. The pregnant women with periodontal disease are 7.5 times more likely to have a pregnancy complication. ${ }^{6,7}$ Pregnant women should be considered as a prime target group for oral health education. ${ }^{4}$ It is strongly recommended that dental examination by a dentist/trained medical staff of all the antenatal cases should be mandatory in outpatient department of maternity hospital. A dental examination and appropriate dental care should become integral part of the routine management of every pregnant woman and that of the medical curriculum.

\section{REFERENCES}

1. Suresh L, Radfar L. Pregnancy and lactation. Oral Surgery Oral Medicine Oral Pathology Oral Medicine. 2004;97(6):672-682.

2. Amporn Dejpitak. The Chiang Mai Dental Public Health Annual Report. 2008;10-12, Chaing Mai Public health Office, Chiang Mai.

3. Cuco G, Fernandez-Ballart J, Sala J et al. Dietary pattern and associated lifestyle in preconception, pregnancy and postpartum. Eur J Clin Nutr, 2006; 60:364-371.

4. Honkala S, Al-Ansari J. Self reported oral health, oral hygiene habits, and dental attendance of pregnant women in Kuwait. J Clin Periodontal. 2005; 32:809-814.

5. Silk H, Douglass $A B$ et al. Oral health during pregnancy. Am Fam Physician, 2008; 77:11391144.

6. Jeffcoat MK, Hauth JC, Geurs NC et al. Periodontal disease and preterm birth: results of a pilot intervention study Periodontal. 2003 Aug; 74(8) 1214-18.

7. Xiong X, Buekens P, Vastardis S, et al. Periodontal disease and pregnancy outcome. State of the science. Obstet Gynecol Surv.2007 Sep;62(9):60515.

DOI: $10.5455 / 2320-1770 . i j r \operatorname{cog} 20131206$

Cite this article as: Gupta B, Siddique A. A study of association between dental health status and pregnancy. Int J Reprod Contracept Obstet Gynecol 2013;2:521-3. 